\title{
ACESSIBILIDADE EMOCIONAL
}

\author{
DUARTE, Cristiane Rose de Siqueira (1) \\ COHEN, Regina (2)
}

(1) Universidade Federal do Rio de Janeiro (UFRJ), Doutora

e-mail: crsduarte@gmail.com

(2) Universidade Federal do Rio de Janeiro, Doutora

e-mail: arquitetareginacohen@gmail.com

\begin{abstract}
RESUMO
Este trabalho sustenta que, muito mais do que respeitar as normas vigentes, a Acessibilidade deve ser encarada como uma oportunidade de construir espaços mais agradáveis, que proporcionem ao usuário a sensação de acolhimento e o afeto pelo Lugar. Nesse sentido, propõe-se o conceito de "Acessibilidade Emocional" como premissa projetual para atingir uma empatia espacial tanto em projetos de Arquitetura e Urbanismo como de Ergonomia e Design. Para ilustrar, o artigo comenta uma experiência didática no curso de Mestrado Profissional do PROARQ/UFRJ que teve a proposta de aplicar o conceito de "Acessibilidade Emocional" em projetos de revitalização do Patrimônio.
\end{abstract}

Palavras chave: Acessibilidade Emocional; Afeto; Experiência

\begin{abstract}
The present paper argues that, beyond respecting current norms, Accessibility should be seen as an opportunity to establish more pleasant spaces that provide the user with a sense of wellcomeness and affection for the Place. In this sense, the concept of "Emotional Accessibility" is proposed as a fundamental premise to achieve spatial empathy in both Architecture and Urbanism and Ergonomics and Design projects. To illustrate this paper's claims, the article relies on a didactic experience in the Professional postgraduate course at PROARQ / UFRJ that applied the concept of "Emotional Accessibility" in projects on heritage revitalization.
\end{abstract}

Keywords: Emotional Accessibility; affection for the Place; Experience.

\section{INTRODUÇÃO}

Como resultado da luta dos movimentos sociais pelos direitos das pessoas com deficiência, - Brasil alcançou algumas conquistas no que tange à acessibilidade em nossas cidades. Esse crescimento, contudo, não surge na velocidade que almejamos, mas são visíveis as mudanças ocorridas nos últimos vinte anos.

Apesar desse pequeno avanço, poucas cidades conseguem oferecer uma real agradabilidade espacial, que leve seus habitantes a terem prazer de compartilhar seus espaços. Percebemos que os planejadores, designers urbanos e arquitetos buscam atender às normas vigentes, porém, sentimos que não existe a consciência de que um projeto dotado de uma acessibilidade mais generosa poderia ampliar os laços de afeto que as pessoas desenvolvem com a cidade. 


\section{(x) $^{\text {enac }}$}

O presente artigo busca discutir essa questão, que será ilustrada com uma experiência didática efetuada no âmbito do Mestrado Profissional do PROARQ/UFRJ, onde buscou-se sensibilizar o profissional experiente para novas visões mais holísticas do espaço.

\section{ARGUMENTAÇÃO TEÓRICA}

As discussões que aqui trazemos se apoiam na capacidade dos espaços construídos de gerar empatia espacial e sensação de acolhimento em seus usuários. Nesse sentido, a fim de fundamentar essas discussões, acreditamos ser necessária uma breve explanação sobre a noção de "Empatia Espacial" e sobre o conceito de "Acessibilidade Emocional".

\subsection{Empatia Espacial}

A empatia, como se sabe, é a capacidade de nos colocarmos no lugar do Outro. Já a "Empatia Espacial" se volta para a capacidade dos espaços de produzirem nas pessoas um reconhecimento de si mesmos nos ambientes (DUARTE, 2015). Esse conceito tem sido explorado por autores advindos de diversas áreas do conhecimento, desde as neurociências até o design urbano, passando pela filosofia e pela psicologia.

Desde os anos 1940, os estudos vinculados à fenomenologia já compreendiam que a consciência que temos de nosso corpo não se restringe a seus limites físicos. Nossos sentidos são capazes de alargar o nosso Eu para além do que podemos tocar com as mãos e se conecta a tudo o que conseguimos enxergar, sentir, tocar, cheirar. É com esse corpo expandido pelos sentidos que desenvolvemos nossa compreensão não apenas da ambiência que nos envolve como também de nosso pertencimento de mundo.

Cientificamente, os trabalhos de neurocientistas (BERTHOZ, 2013) mostram que esse deslocamento emocional para além de si mesmo ativa zonas cerebrais que também são responsáveis pelo deslocamento espacial. Com isso é possível explicar porque os espaços das cidades podem, muitas vezes, ser compreendidos como partes de nós mesmos. Mas para que exista esse sentimento deve haver uma sintonia, uma ressonância, que nos conecta com a ambiência à nossa volta. A essa ressonância chamamos Empatia Espacial ${ }^{1}$.

Podemos dizer que muitas vezes um espaço demora a nos "conquistar" e nem sempre "consegue". Essa forma de encarar o espaço personificando-o demonstra um potencial de construção de narrativas e de diálogo entre pessoas e o espaço. É justamente esse potencial de diálogo que emerge quando o espaço "demonstra" acolher seus visitantes, quando nele há indícios de que seus usuários são bem-vindos, predispondo o sujeito a estabelecer o "pacto" entre si e o mundo, como dizia Merleau-Ponty².

A convicção da importância dessa temática para o embasamento de projetos de espaços arquitetônicos e urbanos fez-nos levar a questão da Empatia Espacial para os estudos sobre acessibilidade. Efetivamente, sabemos há uma aderência dos princípios do Desenho Universal com a questão do acolhimento que um espaço pode oferecer a todas as pessoas. Foi nesse contexto que desenvolvemos o conceito de "Acessibilidade Emocional".

\footnotetext{
${ }^{1}$ A empatia espacial não deve ser confundida com "simpatia" pelo lugar. Essa ressonância pode ocorrer mesmo se estivermos tristes e sentirmos que a ambiência à nossa volta acompanha nossos sentimentos; podemos, da mesma forma, estar exultantes e sentir como se toda a cidade vibrasse conosco.

2 Referimo-nos à experiência no espaço, que produz a percepção de harmonia a partir do estabelecimento de relações com o Lugar, quando parece haver um "pacto, estabelecido [...] entre nosso corpo e o mundo, entre nós mesmos e nosso corpo" (MERLEAU-PONTY, 1945, p.293).
} 


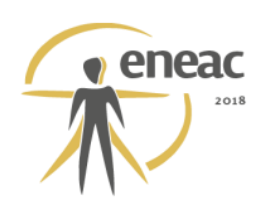

\subsection{Acessibilidade Emocional}

Sustentamos que um espaço só é plenamente acessível quando é capaz de transmitir ao usuário a sensação de acolhimento; quando são respeitados os aspectos emocionais, afetivos e intelectuais, indispensáveis para o estabelecimento de ligações entre o usuário e o Lugar. Foi nesse sentido que desenvolvemos o conceito de "Acessibilidade Emocional" (DUARTE e COHEN, 2012), que tem como pressuposto que apenas uma boa acessibilidade física ao espaço não é suficiente para gerar empatia espacial e promover condições agradáveis de experienciação do Lugar ${ }^{3}$.

A "Acessibilidade Emocional" significa, portanto, a capacidade do Lugar de acolher seus visitantes, de gerar afeto, de despertar a sensação de fazer parte do ambiente e de se reconhecer como pessoa bem-vinda. Esse conceito destitui a ideia de que a acessibilidade acontece apenas com a supressão de barreiras físicas. Assim, a "Acessibilidade Emocional" engloba toda a ambiência que envolve o usuário do lugar, tratando-o como um ser total, capaz de ativar sistemas complexos de relação com o espaço e com o Outro.

Por preocupar-se com o sentimento de afeto que os ambientes podem proporcionar nas pessoas, a "Acessibilidade Emocional" abrange também a sensorialidade, as diferenças físicas e os aspectos subjetivos. A importância da compreensão da sensorialidade põe a luz no reconhecimento do corpo como baluarte da emoção (LE BRETON, 2009). Por meio dos sentidos, o corpo estabelece a relação do Eu no mundo e transforma-se no comunicador simbólico da emoção experimentada. Portanto, para estimular a construção de afetos pelo Lugar, o corpo deve ser considerado em sua diversidade física, social, política, cultural e ambiental.

Temos verificado em nossas pesquisas que essas ideias são ainda pouco exploradas por projetistas das áreas de arquitetura e design urbano ${ }^{4}$. Por mais que esses profissionais declarem compreender que projetar para todos significa também promover o acolhimento e o afeto de todos, nem sempre a acessibilidade ampla é eleita como premissa de seus projetos.

Mas, na prática, como seria um projeto fundamentado na "Acessibilidade Emocional"? Estaríamos correndo o risco de permanecer apenas no domínio das ideias utópicas se não testássemos uma aplicação direta desses conceitos em projetos reais.

\section{EXPERIÊNCIA DIDÁTICA}

Habitualmente, o profissional das áreas de ciências sociais aplicadas, sobretudo nas especialidades de arquitetura, desenho urbano e ergonomia, é receptivo em relação ao usuário de seus projetos. É um profissional que trabalha de forma empática: costuma imaginar-se penetrando nos espaços arquitetônicos, admirando um objeto criado; tem geralmente a capacidade de abstrair-se de si mesmo e se colocar em uma situação de estranhamento como se fosse a primeira vez que estivesse vendo algum objeto, ou recebendo o impacto de uma nova webpage, por exemplo.

Contudo, parece-nos que, quando o assunto é acessibilidade, a empatia deixa de existir e o projeto dá mostras de atender às normas como se fossem uma mera obrigatoriedade burocrática. Em nossa busca por espaços acessíveis temos nos deparado majoritariamente

\footnotetext{
3 O conceito de Acessibilidade Emocional desenvolvido por Duarte e Cohen (2012) recebeu, inicialmente, a denominação de "Acessibilidade Plena", termo que foi posteriormente substituído pela alusão ao componente subjetivo da relação com o espaço.

${ }^{4}$ Profissionais entrevistados no âmbito da pesquisa desenvolvida pelo Núcleo Pró-acesso.
} 


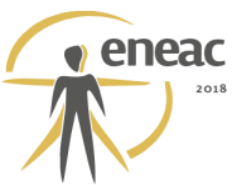

com locais pouco convidativos. Se é assim, por que a questão da acessibilidade não é tratada igualmente de forma empática pelos profissionais das áreas de arquitetura, urbanismo e ergonomia?

Uma das possíveis respostas poderia estar na formação desses planejadores. Sabemos que a capacidade de projetar de forma empática é ensinada a esses profissionais desde o início do seu curso de graduação, principalmente por meio de disciplinas práticas e de simulação. Em nossa experiência didática com a disciplina sobre acessibilidade temos obtido bons resultados $^{5}$, comprovados não apenas pelo relato de alunos como verificados com 0 acompanhamento dos egressos que, em número significativo, produzem espaços agradáveis e acessíveis.

No entanto, caso o despertar desse comprometimento com a acessibilidade mais afetiva dependesse unicamente de disciplinas não obrigatórias no curriculum de formação de arquitetos, dificilmente poderíamos esperar um futuro mais igualitário em nossos espaços. Nesse sentido, indagávamo-nos se um profissional já formado, "calejado" no mercado de trabalho e acostumado a atender às normas e limitações dos códigos vigentes poderia ser sensibilizado - mesmo que tardiamente - para essa nova visão.

A experiência foi feita, então, no âmbito do curso de mestrado profissional do $P R O A R Q^{6}$. Como se sabe, o curso de Mestrado Profissional é voltado para planejadores que não têm tantos vínculos com a teoria, possuindo um perfil muito mais prático. São arquitetos, urbanistas e planejadores que já estão inseridos no mercado de trabalho, em empresas públicas ou privadas, que voltam à academia para reciclar e aperfeiçoar seus conhecimentos em determinado setor.

No referido curso, a disciplina "Arquitetura Inclusiva", ministrada pelas autoras deste texto, estabeleceu-se com base no conceito de "Acessibilidade Emocional" e promoveu debates, workshops de vivência e palestras com pessoas com deficiência, que relatavam muito mais suas experiências afetivas no espaço urbano e arquitetônico do que suas dificuldades com barreiras ou obstáculos. Apesar de práticos e pragmáticos, os debates pautavam-se no trinômio Experiência-Acolhimento-Emoção, buscando revisar a noção de Patrimônio (foco do curso) dentro de um novo plano de necessidades sentimentais para projetos de intervenção / readequação. O conceito de "Acessibilidade Emocional" foi discutido por meio de exercícios de simulação empática do corpo deficiente no espaço projetado, buscando um maior leque de formas de percepção e experiência espacial. Em seguida, foi solicitado aos profissionais inscritos na turma que elaborassem projetos de requalificação de bens patrimoniais existentes, de forma a promover "Acessibilidade Emocional".

Os resultados foram além das expectativas ${ }^{7}$. Os projetos propostos, muito além de medidas de acessibilidade, trouxeram reflexões sobre as dimensões subjetivas e culturais do ambiente construído e sobre a inserção do corpo em espaços estimulantes e acolhedores. Foram propostas formas criativas e críticas para a transformação de bens patrimoniais em espaços de experiência e concretização do exercício de construção da afetividade por cada usuário.

\footnotetext{
${ }^{5}$ A metodologia de ensino sobre acessibilidade ministrada na FAU/UFRJ foi premiada pela European Association for Architectural Education 2003-2004 (ver DUARTE e COHEN, 2003).

${ }^{6}$ Curso de Mestrado Profissional em Projeto e Patrimônio do Programa de Pós-graduação em Arquitetura, Universidade Federal do Rio de Janeiro

7 Devido ao curto espaço imposto pelo presente texto, não será possível descrever os trabalhos que serão, contudo, expostos durante a apresentação no congresso.
} 


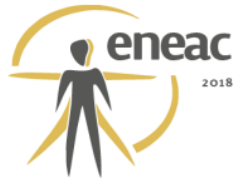

\section{CONSIDERAÇÕES FINAIS}

Somos levados a crer que talvez haja uma lacuna na maneira de ministrar as disciplinas de projeto na formação de arquitetos, urbanistas e designers. Quando é apresentada ao graduando a possibilidade de "adaptar" algo, significa que, a priori, esse algo já não servia para todos. Cria-se assim uma distância, uma objetificação da acessibilidade, que dificulta as ações de projetação empática. Depois de formados, muitos planejadores no Brasil continuam carregando consigo esse distanciamento e ainda têm dificuldade de lidar com o público com deficiência. $O$ espectro de usuários permanece limitado e a acessibilidade só é pensada posteriormente.

Assim, como diz Scott Rains (2011), a acessibilidade segue pela metade na direção da conquista de normas artificiais e fora de contexto de quem é "normal". De acordo com o autor, a acessibilidade constantemente torna-se mera obrigação. Por meio de checklists, considera-se pessoas com deficiência como "problemas" a serem resolvidos e "ticados" quando as normas são atendidas. Dessa forma, aceita-se um desempenho de acordo com o padrão "menos pior", buscando apenas o mínimo que pode ser codificado após o compromisso político da legislação e obrigação. Estabelece-se, assim, um piso, mas geralmente assume-se que o teto está fora de alcance. Essa lógica é materializada em espaços e produtos que não acolhem nem despertam afetos positivos em seus usuários.

No entanto, nossa experiência com arquitetos atuantes no mercado de trabalho no âmbito do curso de Mestrado Profissional nos mostrou que é possível mudar essa perspectiva ao se considerar a importância de uma "Acessibilidade Emocional", sensitiva, generosa. Vimos que, quando o ponto de vista dos usuários é respeitado de forma empática, a experiência toma protagonismo em relação à deficiência.

Não negamos que as Normas Técnicas de Acessibilidade representem conquistas preciosas que devem ser respeitadas, mas entendemos que é possível ir além desses referenciais e, ao repensar a acessibilidade como uma ponte para o afeto pelos lugares, será possível construir espaços e produtos realmente inclusivos.

\section{REFERÊNCIAS BIBLIOGRÁFICAS}

BERTHOZ, Alain. Le changement de point de vue, un élément fondamental de la relation avec autrui et l'empathie. Conferência na École Normale Supérieure de Paris em 10 de janeiro de 2013. Disponível em: http://savoirs.ens.fr/expose.php?id=1036

DUARTE, C. R. S.; COHEN, Regina . Projet GREAUD: L'Enseignement de Architecture Inclusive. In: Ebbe Harder. (Org.). Writings in Architectural Education. Copenhagen: From \& Co., 2003, p. 82-97.

DUARTE, Cristiane Rose de S. e COHEN, Regina. Acessibilidade e Desenho Universal: Fundamentação e revisão bibliográfica. Relatório técnico do Núcleo Pró-acesso, Rio de Janeiro, UFRJ, 2012.

DUARTE, Cristiane Rose de S. e COHEN, Regina. A acessibilidade plena e experiência espacial em espaços inclusivos. In Anais do V ENEAC. Florianópolis, 2013. Versão Digital.

DUARTE, Cristiane Rose de S. A empatia espacial e sua implicação nas ambiências urbanas. In Revista Projetar. Natal, v.1. n.1. Outubro 2015, p. 70-76

LE BRETON, David. As paixões ordinárias: antropologia das emoções. Rio de Janeiro: Vozes, 2009.

MERLEAU-PONTY, Maurice. Phénoménologie de la perception. Paris, Gallimard, 1945

RAINS, Scott. Accessibility is not Inclusion. In: New Mobility Magazine. Janeiro de 2011. Disponível em: http://www.newmobility.com 